\title{
MATHEMATICAL MODELING OF MICROWAVE-VACUUM DRYING OF VEGETATIVE MASS
}

\author{
Sergey Braginets ${ }^{1}$, Artem Rukhlyada ${ }^{1}$, Oleg Bakhchevnikov ${ }^{1}$, Viktor Pakhomov ${ }^{2}$ \\ ${ }^{1}$ Agricultural Research Centre Donskoy, Russia; ${ }^{2}$ Don State Technical University, Russia \\ sbraginets@mail.ru, ruhlada1990@yandex.ru,oleg-b@list.ru,vniptim@gmail.com
}

\begin{abstract}
Preservation of carotene for balancing the ration of animals in winter is important at the current time. It is known that drying is the most common way of preparing food for long-term storage. Elimination of moisture in the material inhibits oxidation of nutrients, development of pathogenic microflora, deterioration of the organoleptic properties of the product, and significantly reduces its technological volume. The process of drying to the conditioning humidity is quite long and energy-intensive, since the vast majority of useful substances of plant tissues are characterized by low thermal stability. To intensify the process of drying the vegetative mass allows the use of microwave radiation. The aim of the study is the mathematical description of microwave-vacuum drying of vegetative plant mass. The study was performed on the experimental setup of the waveguide type with increased intensity of exposure. The physical model of the process of dehydration with the addition of the parameters of the emitter of microwave energy and dielectric properties of dissipative material inside the drying chamber were considered. The mathematical model includes the system of equation changes in the physical and dielectric properties of the product in the steady state dehumidification. Implementation of mathematical models in the computational environment, such as MathCAD, allows to calculate the modes of equipment, depending on the varying properties of the dried product. Ultimately, the research will help design the installation of microwave drying with better performance and wide application.
\end{abstract}

Keywords: mathematical model, microwave energy, vacuum, drying, vegetative mass.

\section{Introduction}

It is known that drying is the most common way of preparing food for long-term storage. Elimination of moisture in the material inhibits oxidation of nutrients, development of pathogenic micro flora, deterioration of the organoleptic properties of the product, and significantly reduces its technological volume. In turn, the process of drying to the conditioning humidity is quite long and energy-intensive, since the vast majority of useful substances of plant tissues are characterized by low thermal stability [1]. The use of microwave radiation allows intensifying the process of drying the plant mass.

Conveyor type apparatuses [2] for drying of spicy food products (garlic, pepper, paprika, etc.) and medicinal herbs are of wide use. Having a high cost and dimensions, these types of installation are profitable only in industries with a sufficiently large surplus value, such as the food, chemical, pharmaceutical industries, as well as sublimation installations.

In animal husbandry and, especially, in poultry farming, the addition of the dried vegetative mass of leguminous grasses in the form of herbal flour in rations makes it possible to balance the rations for carotene and protein in a qualitative way. At the same time, the task is not only to prepare feed with the least expenditure of resources, but also to save it until the next vegetative season with the least loss of nutrients. The investigations $[3 ; 4]$ showed that intense exposure to the microwave field allows for a carotene-stabilizing effect. Due to the coagulation of plant cell protoplasm, there is an effect of clogging of unstable substances to oxidation, that increases the storage of granulated grass meal in warehouses until 6-8 months under normal conditions with carotene losses of no more than $20 \%$. To obtain intensive exposure of microwave radiation to wet vegetative mass, it is reasonable to use a device with a waveguide chamber with a longitudinal movement of the processed product [5].

The main difference between waveguide cameras of a pass-through type and resonator ones is that all energy is consumed in the chamber with minimal losses and the design makes it possible to organize the process of processing both a periodic and a continuous mode [6]. The use of vacuum in the chamber to drain the evaporated moisture makes possible to increase the drying efficiency. In addition, the evacuation of the chamber reduces the boiling point of water on the surface of the processed material, thereby maximally preserving the thermally unstable substances in the finished product, including $\beta$-carotene.

To select rational operating modes of the drying device with microwave energy suppliers and to transfer them on the industrial samples, there is a necessity for a mathematical description of the 
processes. The study of the microwave processing of various materials using mathematical modeling has been successfully practiced for a long time [7-10].

The research objective consisted in compilation of a mathematical model of microwave-vacuum drying of vegetative mass of the empirical formulas offered by different researchers and the precheck experimental validation of its applicability for a choice of rational operation modes of the drying apparatus.

\section{Materials and methods}

The main assumptions underlying the construction of the mathematical model of microwave drying will be formed as follows: in the considered time interval the drying material mass inside the chamber is stationary, the conductive heating of the mass from the walls of the waveguide, as well as the heat exchange of the material with the surroundings is negligibly small. The material is heated due to a flat electromagnetic wave, the energy transfer by thermal conductivity to the non-irradiated volume during the time of irradiation is absent, and there is no re-condensation of the vapor.

Drying of the grinding green alfalfa was carried out at the constant power consumption of a microwave generator of $800 \mathrm{~W}$ and frequency of $2450 \mathrm{MHz}$. The heating temperature of alfalfa changed at the range from 120 to $185^{\circ} \mathrm{C}$. The low atmospheric pressure of $80 \mathrm{kPa}$ was created in the drying chamber. Moisture content of alfalfa was determined by a drying method in a drying oven at a temperature of $105^{\circ} \mathrm{C}$ until stabilization of the mass. The moisture content was measured as the specific content of water in alfalfa lump expressed as a percentage. The drying rate was measured as the change of moisture content of alfalfa during its moving through one section of the drying chamber.

\section{Results and discussion}

Let us consider a mathematical description of the process of the material drying with a flat microwave front. Let us imagine a physical model of the microwave effect in a waveguide (part configuration $90 \times 45 \mathrm{~mm}$ ). The material with dielectric characteristics $\varepsilon^{\prime}, \varepsilon^{\prime \prime}$ is located in the microwave field (Fig. 1). $\varepsilon^{\prime}$ reflects the ability of a drying material to store electromagnetic energy, $\varepsilon^{\prime \prime}$ measures the ability of a material to dissipate electric energy as heat. Literal notations in Fig. 1 are decrypted in explanations to formulas (1-13).

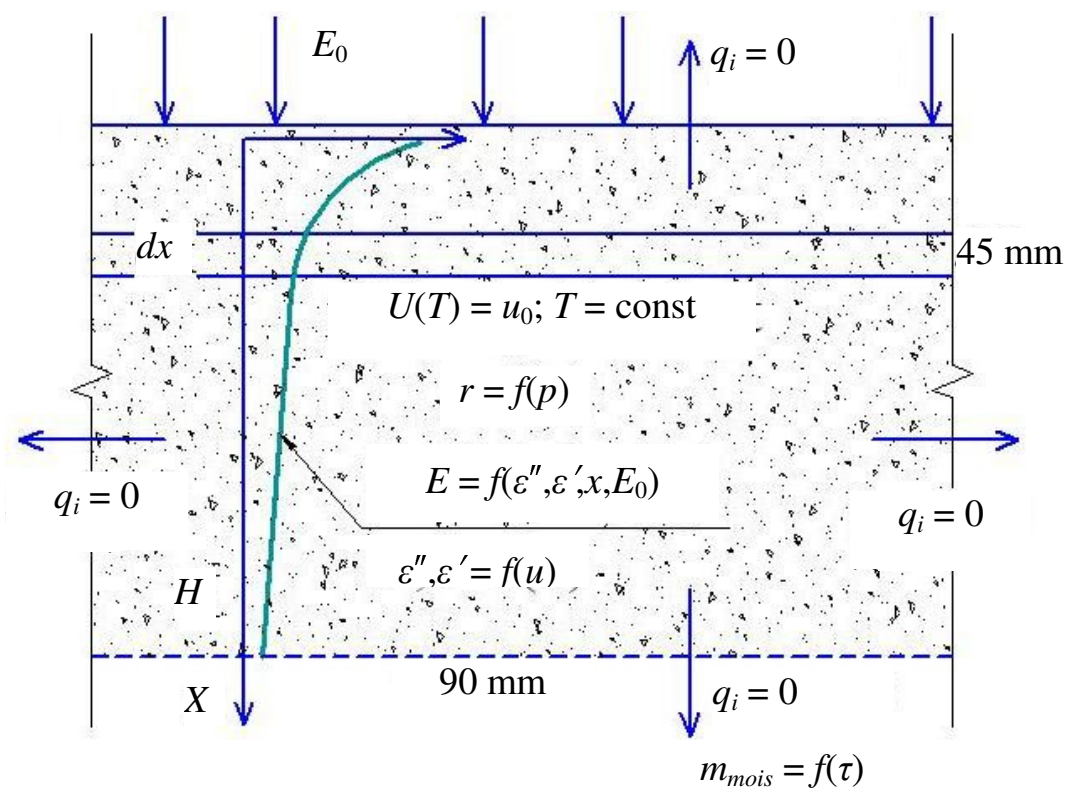

Fig. 1. Physical model of microwave drying

Let us consider the flow of moisture transfer in the material. The material here is understood as the monolith of the chopped vegetative mass in the drying chamber, in which dissipation of microwave energy takes place. 
As the process of evaporation occurs under isothermal conditions (the stage of intensive drainage of moisture) and there is no condensation (due to sufficient depletion), the moisture transfer takes place due only to the concentration gradient and is equal to [3]

$$
C^{\text {conc }}=D \cdot \operatorname{grad} \cdot u \text {, }
$$

where $D$ - diffusion coefficient.

The value of $\mathrm{grad} \cdot u$ in the process of dielectric drying depends on the depth of penetration of the microwave field into the material and its dissipative properties, which can be estimated by the duty cycle with some assumption.

The rational density of the dried mass $\rho=220 \mathrm{~kg} \cdot \mathrm{m}^{-3}$ [11] obtained as a result of preliminary studies corresponds to a duty cycle of 0.79 to 0.85 , hence we can assume that the vaporization inside the monolith under consideration takes place at the same temperature, since the vacuum losses inside the monolith are neglected. Considering the structure of the dried mass, we can note that the diffusion transfer of moisture is possible only within one particle (according to capillaries of the stem) and in the total energy balance it is negligibly small, hence the local change in the liquid concentration is due only to its phase transformation [12]

$$
\frac{d u}{d \tau}=-l_{v}
$$

Let us consider a local change in the moisture content in the material layer $d x$ in a time $d \tau$. The loss of moisture mass is associated with a change in the moisture content [13]:

$$
d u=\frac{d m_{m o i s}}{m_{1}} \text {. }
$$

where $d m_{\text {mois. }}-$ loss of moisture, $\mathrm{kg}$;

$m_{1}$ - mass of the material considered to be dried over a given period of drying, $\mathrm{kg}$.

As it has been mentioned above, the loss of moisture mass is determined by its evaporation by the action of a volumetric heat source with specific power $q_{\mathrm{i}}[13]$

$$
d m_{\text {mois }}=\frac{q_{i} V d \tau}{r_{p}}
$$

where $\mathrm{q}_{\mathrm{i}}-$ specific power, $\mathrm{V} \cdot \mathrm{m}^{-1}$;

$V$ - volume of a layer $d x, \mathrm{~m}^{3}$;

$r_{p}-$ specific heat of vaporization at pressure $p$ [13], $\mathrm{J} \cdot \mathrm{kg}^{-1}$.

Approximating the source data [13] in the pressure range of 40-100 $\mathrm{kPa}$ physical quantity of $r_{p}$ can be adequately described by the model

$$
r_{p}=58.56 p^{2}-182.2 p+2382,
$$

where $p$-average pressure in the waveguide chamber, $\mathrm{Pa}$.

As $m_{1}=V \cdot \rho_{1}$, where $\rho_{1}$ - density of conditionally dry material in the waveguide chamber, then we can write the equations (1) and (2) in such a way $[12 ; 13]$

$$
\frac{d u}{d \tau}=-\frac{q_{i}(x)}{\rho_{1} r_{p}} .
$$

The specific power $q_{\mathrm{i}}$ is a function of the electric field strength $E$ and the dielectric characteristics of the material [14]

$$
q_{i}=2 \pi \cdot f \cdot \varepsilon_{0} \cdot \varepsilon \cdot|E|^{2},
$$

where $f-$ frequency of the electromagnetic field, $f=2450 \mathrm{MHz}$;

$\varepsilon_{0}-$ universal dielectric constant. 
The electric field strength in the layer $d x$ [14]

$$
E=E_{0}(\tau) \cdot e^{-x / \delta_{p}}, \mathrm{~V} \cdot \mathrm{m}^{-1},(5)
$$

where $E_{0}(\tau)$ - strength of the electric field in the material at the boundary of the interface, $\mathrm{V} \cdot \mathrm{m}^{-1}$.

Power penetration depth of electromagnetic waves into the material is defined as the distance at which the power decreases in $e^{-\tau}$ times $(e=2.7183)[14]$

$$
\delta_{p}=\frac{c}{2 \pi f \sqrt{2 \varepsilon^{\prime}}}\left[\sqrt{1+\left(\frac{\varepsilon^{\prime \prime}}{\varepsilon^{\prime}}\right)^{2}}-1\right]^{1 / 2},
$$

where $c$-speed of light, $3 \cdot 10^{8} \mathrm{~m} \cdot \mathrm{s}^{-1}$.

Under certain conditions of constant frequency and a sufficiently narrow temperature range of 20$100{ }^{\circ} \mathrm{C}$, there are empirical correlations of the material properties and the conditions of the drying process.

The system of the polynomial equations of the process of drying in relation to vegetables and fruit is offered by O. Sipahioglu et al. [15]. For the conditions more appropriate for the drying of leguminous grasses, it is reasonable to use the dependences characterizing the dielectric parameters of vegetables, because of the high sugar content in the fruit [15]

$$
\begin{gathered}
\varepsilon^{\prime}=-243.6+1.342 T+4.593 U-426.9 A^{2}-0.01415 U T-0.3151316 .2 A T, \\
\varepsilon^{\prime \prime}=-100.02-0.1611 T+0.001415 T^{2}+2.49 U-378.9 A+316.2 A^{2},
\end{gathered}
$$

where $T$ - temperature, ${ }^{\circ} \mathrm{C}$;

$U$ - moisture content, \%;

$A$ - ash content, $\%$.

The strength of the electric field in the material at the interface depends on the dissipation of the electromagnetic wave due to inconsistency of the surrounding.

For the considered grade of raw material [14]

$$
E_{0} \approx E_{B}\left(\frac{2}{1+\sqrt{\varepsilon_{B}^{\prime}}}\right),
$$

where $E_{\mathrm{B}}$ - intensity of the electric field in the air with an ideal matching of surrounding (lack of material), $\mathrm{V} \cdot \mathrm{m}^{-1}$

$\varepsilon_{B}^{\prime}$ - relative permittivity of the wet material at the boundary of the interface (variable during the drying process), $\mathrm{V} \cdot \mathrm{m}^{-1}$.

The system of equations (2-9) must be supplemented by the initial condition

$$
u(x, 0)=u_{0} .
$$

When the material moves along the waveguide, it is also necessary to take into account the energy expended on heating the material to the boiling point. Considering the heating process from the point of view of thermal properties, the energy for heating is determined by the dependence [12]:

$$
P=\frac{c_{h} m \Delta T}{\tau}=c_{h} Q \Delta T, \mathrm{~J} \cdot \mathrm{s}^{-1},
$$

where $Q$ - submission of material, $\mathrm{kg} \cdot \mathrm{s}^{-1}$;

$c_{h}$ - heat capacity of the heated material, $\mathrm{J} \cdot\left(\mathrm{kg} \cdot{ }^{\circ} \mathrm{C}\right)^{-1}$.

As the heat engineering properties of the chopped plant mass are quite variable and depend on the density, humidity, particle size, they can be approximately described in the model by moisture and ash content [16]

$$
c_{h}=4200 U \cdot 0.01+880 A \cdot 0.01,
$$


where $0.01-$ conversion factor of the units of measure expressed as a percentage.

In this case, the time of the material in the microwave radiation area consists of the time of water heating and evaporation.

Taking into consideration that the power released in the dielectric material is determined [17]:

$$
F=5.56 E^{2} \cdot \varepsilon^{\prime \prime} \cdot f \cdot 10^{-11}, \mathrm{~W} \cdot \mathrm{m}^{-3} .
$$

Then the time of the direct moisture transfer process is:

$$
\tau=\frac{\rho a b \delta_{p}}{Q}-\frac{c_{h} m_{0} \Delta T}{a b z \cdot 5.56 E^{2} \varepsilon^{\prime \prime} \cdot f \cdot 10^{-11}},
$$

where $a, b$-part configuration of waveguide, $\mathrm{m}$;

$m_{0}$ - some mass heated up to the boiling point when moving inside the waveguide at distance $z, \mathrm{~kg}$.

Thus, the system of equations (2-13) is closed and represents a mathematical description of the removal of moisture from a layer of material under isothermal conditions in the field of a progressive microwave.

As the considered quantities are in the criteria relationship to each other, there is a need for modeling. On the basis of the ratio, there have been developed the programs for modeling microwave drying processes for waveguide installations using the MathCAD environment. The output criterion of the model is the moisture content, which is equal to the amount of moisture removed from the raw material during a single pass through the chamber with one magnetron.

The adequacy of the model has been verified on a developed laboratory microwave-vacuum drying apparatus of continuous operation for drying the vegetative mass [5] (Fig. 2).

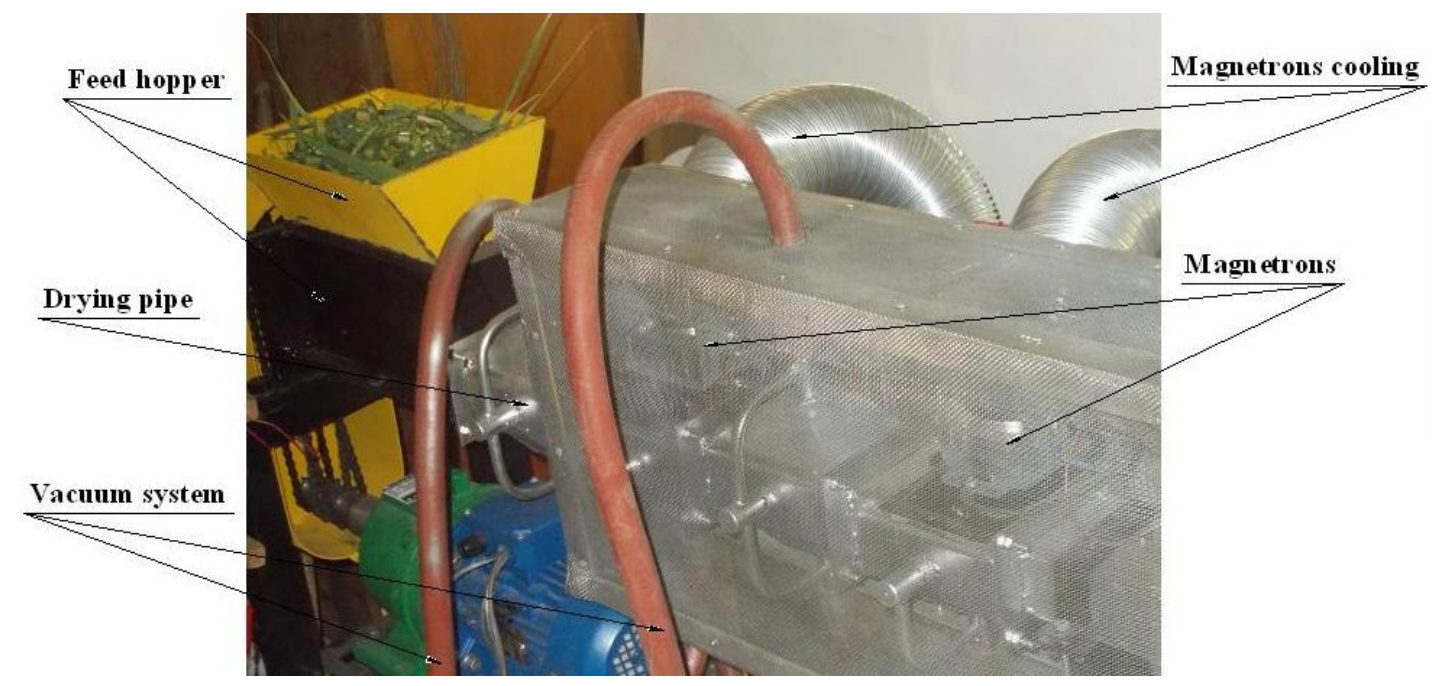

Fig. 2. Laboratory microwave-vacuum drying apparatus

The calculation algorithms include the steps:

1. The parameters of the apparatus are entered: the density of the flow and frequency of microwave oscillations from the characteristics of the magnetron, the depth of vacuum in the chamber, the geometric dimensions of the waveguide;

2. The modes of the apparatus regime are set up: the amount of material supply and its initial temperature (in the experiment it is $20^{\circ} \mathrm{C}$ );

3. Changing the initial moisture content of raw materials in the range of $\mathrm{W}=80-15 \%$, we obtain the dependence of the moisture content on the initial moisture content of the raw materials. The study in the moisture content was carried out according to standard procedures [18].

At such initial values of raw materials as alfalfa of the second cut in the phase of budding, the average degree of chopping of 10-12 mm, moisture content of $78 \%$, density inside the drying chamber 
of $220 \mathrm{~kg} \cdot \mathrm{m}^{-3}$, pressure to the steam-conducting system of $80 \mathrm{kPa}$, we obtain the experimental curve of the moisture content during microwave-vacuum drying.

The results of modeling and experimental study are shown in Fig. 3. This diagram showed the change of the moisture content in the dried alfalfa depending on the initial moisture content of green alfalfa.

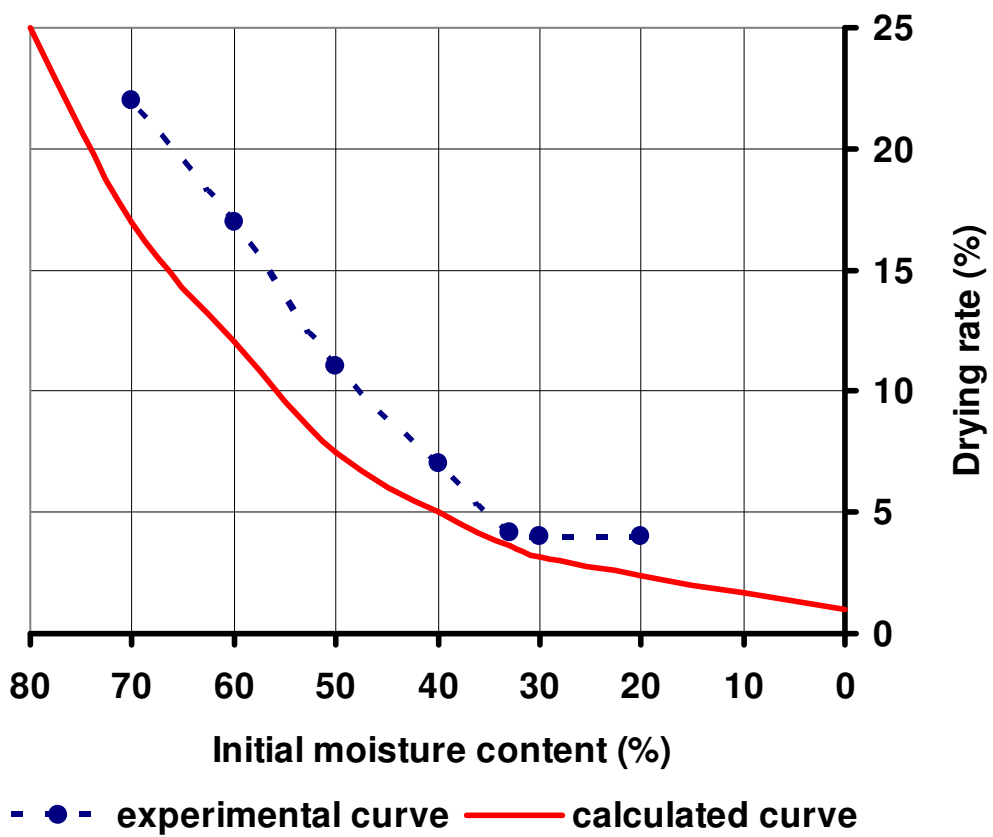

\section{Fig. 3. Results of modeling and experimental study of microwave-vacuum drying of vegetative mass of alfalfa}

The diagram shows that the developed compilation model quite accurately describes the process of microwave-vacuum drying of the vegetative mass of green plants with the assumed assumptions. The observed equidistance of the calculated and experimental curves is due to various causes, such as the wavy nature of the field distribution, the thermal losses of the waveguide, and the morphological and dielectric characteristics of the raw plant material. In our opinion, incomplete compliance of the values of dielectric characteristics of vegetative mass calculated on formulas $(7,8)$ to real characteristics hypothetically is the basic reason of the observed difference of the curves. Formulas for computation of dielectric characteristics of vegetative mass of green plants need to be specified. The fact of inflection of the experimental curve hypothetically is interpreted by the fact that deleting of chemically bound moisture from the vegetative mass begins in case of the green plant moisture content of $32-33 \%$. This phenomenon needs to be considered by development of a mathematical model of microwave-vacuum drying.

The coefficient of determination $\left(R^{2}\right)$ was used for verification of the model. The predicted drying rate in the vegetative mass matches tolerably with the experimental data, the coefficient of determination $R^{2}$ of 0.88 in Page Model and 0.82 in Exponential Model. Statistical parameters are not written because of the limited size of the article.

\section{Conclusions}

Amathematical model of microwave-vacuum drying of vegetative mass is developed on the basis of researches of different authors. The model is a system of equations describing the process of heating of vegetable vegetative mass by microwave radiation. The model considers influence of dielectric characteristics of the plant material and the heat flow on the intensity of the drying process. The adequacy of the model has been experimental verified on a developed laboratory microwavevacuum drying apparatus of continuous operation for drying of vegetative mass. The developed compilation model tolerably describes the process of microwave-vacuum drying of the vegetative mass of green plants with the assumed assumptions. The predicted drying rate in vegetative mass 
matches tolerably with the experimental data, the coefficient of determination $\mathrm{R}^{2}$ of 0.88 in Page Model and 0.82 in Exponential Model. The observed equidistance of the calculated and experimental curves is due to incomplete compliance of the values of dielectric characteristics of the vegetative mass to real characteristics. The developed mathematical model is suitable for a choice of the rational modes of operation of the microwave-vacuum drying apparatus of continuous action after specification of the dielectric characteristics, calculated formulas and values of the vegetative mass.

\section{References}

[1] Moses J.A., Norton T., Alagusundaram K., Tiwari B.K. Novel drying techniques for the food industry. Food Engineering Reviews, 2014, vol. 6, No 3, pp. 43-55.

[2] Leiker M., Adamska M.A. Energy efficiency and drying rates during vacuum microwave drying of wood. European Journal of Wood and Wood Products, 2004, vol. 62, No 3, pp. 203-208.

[3] Rogov I.A. Biological aspects of microwaves food's technologies. Ehlektronnaja obrabotka materialov (Electronic processing of materials), 2000, No 5, pp. 115-125.

[4] Cui Z.W., Xu S.Y., Sun D.W. Effect of microwave-vacuum drying on the carotenoids retention of carrot slices and chlorophyll retention of Chinese chive leaves. Drying Technology, 2004, vol. 22, No 3, pp. 563-575.

[5] Patent RU 262046. Setting the combined drying green plant mass.

[6] Feldman N.J. SVCH-kamery prokhodnogo tipa i ikh primenenie v ustanovkakh ehlektromagnitnoj obrabotki materialov (Microwave camera of flow type and their application in installations of electromagnetic processing of materials). Sovremennaja ehlektronika (Modern electronics), 2009, No 8, pp. 66-69. (In Russian)

[7] Motavali A., Najafi G.H., Abbasi S., Minaei S., Ghaderi A. Microwave-vacuum drying of sour cherry: comparison of mathematical models and artificial neural networks. Journal of food science and technology, 2013, vol. 50, No 4, pp. 714-722.

[8] Feng H., Yin Y., Tang J. Microwave drying of food and agricultural materials: basics and heat and mass transfer modeling. Food Engineering Reviews, 2012, vol. 4, No 2, pp. 89-106.

[9] Zhang J., Luo Y., Liao C., Xiong F., Li X., Sun L., Li X. Theoretical investigation of temperature distribution uniformity in wood during microwave drying in three-port feeding circular resonant cavity. Drying technology, 2017, vol. 35, No 4., pp. 409-416.

[10] Horuz E., Bozkurt H., Karataş H., Maskan, M. Simultaneous application of microwave energy and hot air to whole drying process of apple slices: drying kinetics, modeling, temperature profile and energy aspect. Heat and Mass Transfer, 2018, vol. 54, No 2, pp. 425-436.

[11] Pakhomov V.I., Braginets S.V., Bakhchevnikov O.N., Rukhljada A.I. Issledovanie processa vakuumnoj SVCH-sushki zelenoj rastitel'noj massy (Research of process of microwave vacuum drying of green vegetable material). Izvestija Gorskogo gosudarstvennogo agrarnogo universiteta (Proceedings of Mountain state agricultural university), 2016, vol. 53, No 4, pp. 187-192. (In Russian)

[12] Lykov A.V. Teplomassoobmen (Heat mass exchange). Moscow: Ehnergija, 1978. 480 p. (In Russian)

[13] Rivkin S.L., Aleksandrov A.A. Teplofizicheskie svojstva vody i vodjanogo para (Heatphysical properties of water and water steam). Moscow: Ehnergija, 1980. 424 p. (In Russian)

[14] Chen G., Wang W., Mujumdar A.S. Theoretical study of microwave heating patterns on batch fluidized bed drying of porous material. Chemical Engineering Science, 2001, vol. 56, pp. 68236835.

[15] Sipahioglu O., Barringer S.A. Dielectric Vegetables and Fruits as a Function of Temperature, Ash, and Moisture Content. Journal of Food Science, 2003, vol. 68, No 1, pp. 234-239.

[16] Mohsenin N.N. Thermal properties of foods and agricultural materials. New York: Gordon and Breach Science Publishers, 1980. 407 p.

[17] Venkatesh M. S., Raghavan G. S. V. An overview of microwave processing and dielectric properties of agri-food materials. Biosystems Engineering, 2004, vol. 88, No 1, pp. 1-18.

[18] Karimi F. Properties of the drying of agricultural products in microwave vacuum. Journal of Agricultural Technology, 2010, vol. 6, No 2, pp. 269-287. 